\title{
Increased carbon footprint of materials production driven by rise in investments
}

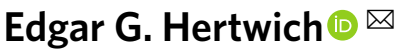

\begin{abstract}
The production of materials is an important source of greenhouse gas emissions. To reduce emissions, policies aim to enhance material efficiency and the circular economy, but our understanding of the dynamics of material-related greenhouse gas emissions is limited. Here, I quantify the greenhouse gas emissions from material production and the carbon footprint of materials in industries that are the first users of materials, and in final consumption, using a multiregional input-output model of the global economy and the hypothetical extraction method. From 1995 to 2015 , greenhouse gas emissions from just material production increased by $120 \%$, with 11 billion tons of $\mathrm{CO}_{2}$-equivalent emitted in 2015 . As a proportion of global emissions, material production rose from 15 to $23 \%$. China accounted for $\mathbf{7 5 \%}$ of the growth. In terms of the first use of materials, two-fifths of the carbon footprint of materials is attributed to construction, and two-fifths to the manufacturing of machinery, vehicles and other durable products. Overall, the replacement of existing or formation of new capital stocks now accounts for $60 \%$ of material-related emissions. Policies that address the rapidly growing capital stocks in emerging economies therefore offer the best prospect for emission reductions from material efficiency.
\end{abstract}

$\mathrm{t}$ is now widely acknowledged that material production causes over half of greenhouse gas (GHG) emissions from industry ${ }^{1-4}$ and that material efficiency ${ }^{5-7}$ and the circular economy ${ }^{8-10}$ are important strategies to reduce those emissions. The International Energy Agency (IEA) ${ }^{2,11}$ traces energy use and direct emissions from production processes of high-volume materials-iron and steel, cement, chemicals and petrochemicals, aluminium, and pulp and paper. Not all materials are covered, emissions associated with non-energy inputs are ignored, and there is little information on the use of materials in the economy ${ }^{12}$. Individual technology case studies, for example, of buildings, infrastructure and vehicles, show an important contribution of materials to the life-cycle impact of those systems and indicate potential synergies and trade-offs between energy and material efficiencies ${ }^{4,13}$. The lack of a comprehensive understanding may impair the development of material efficiency or circular-economy strategies for climate change mitigation ${ }^{12}$.

Here, I present the first analysis, to my knowledge, of the contribution of material production to the carbon footprint of products and final consumption between 1995 and 2015, analyse the use of materials by downstream fabrication and manufacturing processes, and quantify the global GHG emissions in the production of materials by type of material. On the basis of the system of national economic and environmental accounts, data on economic activity, energy and material conversion and use, and resulting emissions, researchers recently produced time series of multiregional input-output (MRIO) tables ${ }^{14-16}$. I used the method of hypothetical extraction (HEM) ${ }^{17,18}$ to identify the contribution of materials in the upstream and downstream emission accounts of a global MRIO. The applicability of HEM to global MRIO tables has not been universally recognized ${ }^{19}$. In the Methods, I show that HEM is indeed applicable to global models and I provide a mathematical derivation of the determination of materials' contribution to the footprint of other products and final consumption. The assessment highlights the important contribution of materials that constitute the capital stock-machinery, factories and warehouses-to the carbon footprint of produced products and delivered services, on the basis of a recently developed dataset for the endogenization of the consumption of fixed capital ${ }^{20}$. Finally, the investigation of different final-demand categories shows that capital formation is a more important final-demand driver than household or government consumption.

In conventional footprint analysis, double counting is a serious issue that impacts the usefulness of previous analyses, in particular for assessing the potential contribution of material efficiency to lowering the carbon footprint of products ${ }^{21,22}$. A recent proposal for correcting such double counting was developed in the process of quantifying the carbon footprint of Japan's material use $\mathrm{e}^{23,24}$ and was extended to analyse the environmental and employment impacts of global supply chains ${ }^{25}$. Here I provide an independent derivation of the suggested method ${ }^{23,25}$ to correct for double counting and extend it to downstream impacts. Following the material efficiency literature $^{1-6}$, I address structural and functional materials used to compose products and exclude foodstuff, fuels and chemicals.

\section{GHG emissions from global material production}

GHG emissions from material production increased by $120 \%$ from 5 billion metric tons $\mathrm{CO}_{2}$-equivalent $\left(\mathrm{GtCO}_{2} \mathrm{e}\right)$ in 1995 to $11 \mathrm{Gt}$ in 2015 , raising their share of the global total from 15 to $23 \%$ (Fig. 1a). $\mathrm{CO}_{2}$ equivalents are a metric for GHG emissions where the emissions of methane, nitrous oxide and other minor GHGs are converted to an equivalent amount of $\mathrm{CO}_{2}$ that would produce a comparable amount of climate forcing integrated over a 100-year time horizon. Iron and steel production caused $3.6 \mathrm{GtCO}_{2} \mathrm{e}$ in 2011 , the year with the most reliable data. When corrected for the use of materials in the production of other materials, this amounted to $31 \%(3.3 \mathrm{Gt})$ of all emissions caused by material production (Fig. $1 \mathrm{~b}$ and Table 1). The next most important contributions were from cement, lime and plaster production with $24 \%$, and rubber and plastics including basic plastics with $13 \%$. Non-ferrous metals contributed $10 \%$ and non-metallic mineral products contributed $14 \%$, 

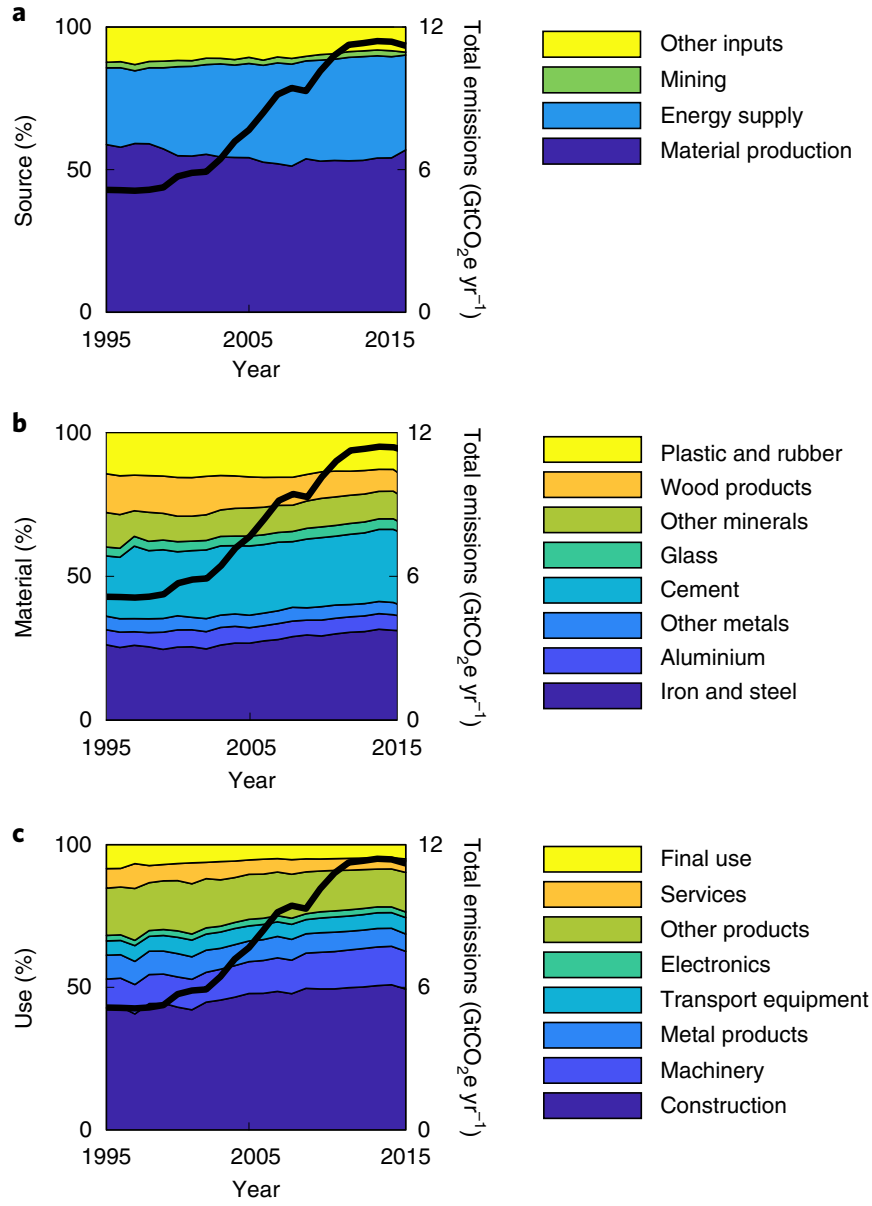

Fig. 1 | GHG emissions from material production. a-c, Three perspectives on the greenhouse emission of material production shown by emitting process (a), class of material (b) and carbon footprint of materials by industry (c). Total emissions are measured in $\mathrm{GtCO}_{2} \mathrm{e} \mathrm{yr}^{-1}$, represented by the black line, which refers to the right $y$ axis. The 100 -year global warming potential was used to convert the climate forcing of GHGs such as methane, nitrous oxide and carbon hexafluoride into an equivalent forcing by $\mathrm{CO}_{2}$.

with glass alone contributing 4\% (Extended Data Fig. 1). Ignoring land-use-related emissions, including deforestation, pulp, paper and wood products, caused a total of $1 \mathrm{Gt}(9 \%)$. Of these materials, the largest growth in emissions was associated with glass; sand and clay; iron and steel; cement, lime and plaster; lead, zinc and tin; and other non-ferrous metal products, which all increased by $160-170 \%$ in the period 1995-2015. The smallest growth was associated with paper, pulp and wood products, stone, copper, and precious metals, but of all materials, only paper increased by less than the total global GHG emissions, $49 \%^{26}$.

In 2011, GHG emissions from the production of materials were $10.8 \mathrm{GtCO}_{2}$ e. Of these emissions, $86 \%$ were $\mathrm{CO}_{2}$, and the remainder was mostly methane associated with energy supply. Direct emissions from material-producing sectors constituted $53 \%$ of the cradle-to-gate emissions of the materials (Fig. 1a), a share that varied from $84 \%$ for cement to $11 \%$ for aluminium (Table $1 \mathrm{a}$ ). Energy supply to material production and other upstream activities contributed $35 \%$ of the total, mining $2 \%$ and other inputs $10 \%$. Emissions associated with the production of fuel and electricity used in mining and of other inputs were counted as energy-sector emissions. If upstream energy was allocated to mining and other inputs, these would contribute 3 and $36 \%$ of emissions, respectively, emphasizing the importance of a life-cycle perspective when determining the emissions of material production.

\section{GHG emissions associated with various uses of materials}

The largest carbon footprints of materials in downstream production were those of cement, lime and plaster in construction $\left(2.5 \mathrm{GtCO}_{2} \mathrm{e}\right.$ in 2011), and of iron and steel used in manufacturing $(2.4 \mathrm{Gt})$. Building and construction was the top designation for other non-metallic minerals including glass, as well as for wood, lead, zinc and tin (Table 1b). Manufacturing was the top destination for rubber and plastics, aluminium, copper, precious metals and other non-ferrous metals.

A more detailed breakdown reveals that iron and steel were used primarily in construction (a carbon footprint of $0.75 \mathrm{GtCO}_{2} \mathrm{e}$ ), in the production of machinery $(1.1 \mathrm{Gt})$, for fabricated metal products $(0.6 \mathrm{Gt})$, for motor vehicles $(0.4 \mathrm{Gt})$ and for other transport equipment $(0.2 \mathrm{Gt})$. Basic plastics corresponding to $0.5 \mathrm{GtCO}_{2}$ e were used in the production of rubber and plastics. Rubber and plastics were used in machinery, motor vehicle and other transport equipment, and final demand (ca. $0.2 \mathrm{Gt}$ each).

When looking at the share of materials in the total carbon footprint of products delivered by different sectors of the economy, materials contributed $70 \%$ to the carbon footprint of construction (Table 2). High fractions were also obtained for electrical machinery and equipment (64\%), machinery (60\%), and other transport equipment $(58 \%)$. Materials contributed $56 \%$ of the carbon footprint of vehicle production. Surprisingly, materials were important for the carbon footprint of some services, contributing $43 \%$ to real estate services, $37 \%$ to computer services, $34 \%$ to post and telecommunications, and $23 \%$ to recreational, cultural and sporting organizations. For services, the use of buildings, equipment and other capital goods were important channels for materials to contribute to carbon footprints. For example, materials in capital goods contributed only $9 \%$ to the carbon footprint of construction, but $27 \%$ to the footprint of post and telecommunications (Table 2). Table 2 contains a weighted global average multiplier of aggregated products, the share of direct emissions, and material and non-material inputs, identified as intermediate or capital inputs.

\section{Final demand drivers of material production}

The immediate demand of materials is often to produce semi-finished products and capital goods, which are then used further to produce consumer goods or services. The material-related footprint of the final demand for services, of the final demand for manufactured products, and of the net investment in additional buildings and infrastructure is $3 \mathrm{GtCO}_{2} \mathrm{e}$ each (Fig. 2a). For services, material-intensive capital goods such as buildings and vehicles are more important than the intermediate input of materials to service production, as Table 2 shows. The final demand for food $(0.6 \mathrm{Gt})$, energy $(0.2 \mathrm{Gt})$ and transport services $(0.2 \mathrm{Gt})$ was less important. Construction and machinery dominate investments, followed by vehicles and electronics. In consumption, services have grown to be important, especially public administration, health and education.

The contribution of materials to the carbon footprint of consumption (and changes in stock and valuables) grew from 4.1 to 7.3 GtCO2e in the period 1995-2015, whereas their contribution to net investment grew fourfold from 1.0 to $4.2 \mathrm{Gt}$ (Fig. 2). The carbon footprint of gross capital formation, which includes all investment, grew from 3.6 to 9.4 Gt (Extended Data Fig. 2), surpassing that of consumption. Gross capital formation is the sum of net capital formation and reinvestment to replace capital that is being consumed (depreciated) in the process of production. Much of the increase in the total emissions from materials production is hence connected to a growth of net investment and the increasing importance of capital to industrial and service production. 
Table 1 | Cradle-to-gate emissions of GHGs associated with the production of materials in 2011

\begin{tabular}{llllllll} 
& $\begin{array}{l}\text { Iron and } \\
\text { steel }\end{array}$ & Aluminium & $\begin{array}{l}\text { Other } \\
\text { metals }\end{array}$ & Cement & Glass & Other minerals $\begin{array}{l}\text { Wood } \\
\text { products }\end{array}$ & $\begin{array}{l}\text { Plastic and } \\
\text { rubber }\end{array}$ \\
\hline GHG emissions $\left(\mathrm{GtCO}_{2} \mathrm{e}\right)$ & 3.3 & 0.58 & 0.49 & 2.6 & 0.42 & 1.0 & 0.97 \\
\hline
\end{tabular}

(a) Location of emissions (\%)

\begin{tabular}{lll} 
Material production & 48 & 11 \\
\hline Energy & 38 & 62 \\
\hline Mining & 2 & 2 \\
\hline Products and services & 12 & 25 \\
\hline
\end{tabular}

$\begin{array}{ll}28 & 84 \\ 33 & 12 \\ 13 & 1 \\ 26 & 3\end{array}$

\begin{tabular}{ll}
25 & 42 \\
48 & 38 \\
\hline 2 & 10 \\
25 & 10 \\
\hline
\end{tabular}

$\begin{array}{ll}33 & 10 \\ 39 & 57 \\ 1 & 1 \\ 27 & 33\end{array}$

(b) Use of materials by industry (\%)

\begin{tabular}{lll} 
Construction & 23 & 5 \\
\hline Machinery, including electrical & 32 & 47 \\
\hline Fabricated metal products & 19 & 19 \\
\hline Transport equipment & 14 & 10 \\
\hline Electronics & 2 & 5 \\
\hline Other products & 3 & 10 \\
\hline Services & 2 & 1 \\
\hline Final consumption & 4 & 3
\end{tabular}

$\begin{array}{ll}25 & 94 \\ 32 & 0 \\ 16 & 0 \\ 3 & 0 \\ 5 & 0 \\ 9 & 1 \\ 3 & 2 \\ 7 & 2\end{array}$

\begin{tabular}{ll}
37 & 70 \\
10 & 4 \\
3 & 1 \\
8 & 2 \\
6 & 1 \\
18 & 7 \\
11 & 5 \\
7 & 10 \\
\hline
\end{tabular}

$\begin{array}{ll}20 & 10 \\ 3 & 14 \\ 1 & 2 \\ 2 & 12 \\ 3 & 8 \\ 32 & 25 \\ 19 & 11 \\ 21 & 17\end{array}$

(c) Carbon footprint of materials in final consumption and net capital formation (\%)

\begin{tabular}{|c|c|c|c|c|c|c|c|c|}
\hline Food & 5 & 5 & 5 & 4 & 9 & 4 & 11 & 8 \\
\hline Clothing & 2 & 2 & 2 & 1 & 2 & 2 & 3 & 4 \\
\hline Shelter & 3 & 3 & 3 & 3 & 2 & 3 & 6 & 4 \\
\hline Transport equipment & 11 & 10 & 6 & 2 & 6 & 4 & 3 & 9 \\
\hline Machinery, including electrical & 15 & 20 & 14 & 2 & 6 & 6 & 3 & 7 \\
\hline $\begin{array}{l}\text { Public administration, health, } \\
\text { education }\end{array}$ & 15 & 16 & 15 & 15 & 17 & 16 & 22 & 18 \\
\hline Real estate services & 6 & 6 & 6 & 8 & 6 & 6 & 5 & 5 \\
\hline Transport services & 3 & 2 & 2 & 3 & 2 & 2 & 2 & 2 \\
\hline Other services & 8 & 8 & 7 & 9 & 7 & 7 & 9 & 8 \\
\hline
\end{tabular}

The share is always the share of total emissions shown in the top line. a-c, Emissions are split by location where emissions occur (a; similar to scope 1, 2 and 3 in the Greenhouse Gas Protocol), the sector buying the materials ( $b$; first user) and the final product that consumers purchase or companies invest in (c).

\section{Rapid growth in emerging economies}

In 2015, slightly more than half of the emissions related to material production occurred in China (Extended Data Fig. 3a). China quadrupled those emissions from 1995, while India and Brazil almost tripled theirs. At the same time, the emissions in Canada, the European Union (EU), Russia and the United States declined by up to one-quarter. Part of the explanation lies in trade. When looking at materials' contribution to the carbon footprint of countries' consumption, only Russia saw a substantial decrease, the EU saw a slight decrease $(-4 \%)$, Canada saw an increase by $30 \%$ and the United States saw an increase by $9 \%$ (Extended Data Fig. 3b). As these post-industrial economies started importing more manufactured products, they also outsourced material production, primarily to China (Extended Data Fig. 3c). Net imports constituted one-third of the material-related carbon footprint of the EU; net exports amounted to $13 \%$ of China's material-related emissions and $18 \%$ of the emissions from the BRITS (Brazil, Russia, Indonesia, Turkey, South Africa).

Three-quarters of the dramatic increase in emissions happened in China. China's net exports rose moderately from 0.3 to $0.6 \mathrm{Gt}$ and hence explains only a small portion of the growth. Instead, it is
China's investment-driven development that serves as explanation for this rapid rise (Fig. 2b): residential floor space increased from 10 to $30 \mathrm{~m}^{2}$ per person ${ }^{27}$, and China built a first-rate high-speed rail network and constructed many roads, bridges, ports and factories. Extending building lifetimes from 23 years to a more normal 60 years $^{28}$, stopping building unoccupied flats ${ }^{29}$, and shifting from construction and heavy industry to services ${ }^{30}$ can dramatically reduce material demand and its associated emissions. Light-weight designs $^{31}$ and low-carbon materials ${ }^{32}$ offer GHG mitigation options for countries entering phases of rapid development, and improvements in reuse and recycling of materials have the largest applicability in developed economies, which have the greatest stocks of manufactured capital ${ }^{33,34}$.

China had been moving towards a service economy and had increased its efficiency ${ }^{30}$. Emissions from cement production had stabilized. Current news, however, indicates that in light of the COVID-19-induced slump in the world economy, China has stimulated investment again, resulting in a rising demand for iron ore on the world market. The overarching importance of the role of investment confirms a previous notion ${ }^{33}$ of infrastructure and durable goods as the main driver of material consumption and related GHG 
Table 2 | Sale-weighted average multipliers of aggregate global sector output at the 17-sector aggregation level, specifying the source of emissions as a share of the multiplier: direct emissions of the sector in question, intermediate inputs and consumption of fixed capital, each separated into material and non-material components

\begin{tabular}{|c|c|c|c|c|c|c|}
\hline \multirow[t]{2}{*}{ GHG emissions multiplier } & \multirow[t]{2}{*}{$\begin{array}{l}\text { Absolute } \\
\left(\mathrm{kgCO}_{2} \mathrm{e} €^{-1}\right)\end{array}$} & \multirow[t]{2}{*}{$\begin{array}{l}\text { Direct } \\
(\%)\end{array}$} & \multicolumn{2}{|r|}{$\begin{array}{l}\text { Inputs } \\
(\%)\end{array}$} & \multicolumn{2}{|r|}{$\begin{array}{c}\text { Capital } \\
(\%)\end{array}$} \\
\hline & & & Material & Non-material & Material & Non-material \\
\hline Agriculture, hunting, forestry and fishing & 2.6 & 66 & 1 & 27 & 3 & 3 \\
\hline Mining and quarrying & 2.3 & 68 & 7 & 18 & 5 & 2 \\
\hline Food production, beverages and tobacco & 1.4 & 11 & 6 & 74 & 5 & 4 \\
\hline Textiles, leather and wearing apparel & 1.5 & 13 & 10 & 64 & 8 & 4 \\
\hline Electrical and machinery & 1.1 & 5 & 45 & 34 & 12 & 5 \\
\hline Transport equipment & 0.9 & 5 & 45 & 33 & 11 & 5 \\
\hline Manufacturing and recycling & 1.3 & 18 & 27 & 42 & 9 & 4 \\
\hline Electricity, gas and water & 8.4 & 74 & 1 & 22 & 2 & 1 \\
\hline Transport & 1.0 & 46 & 4 & 36 & 8 & 6 \\
\hline Post and telecommunications & 0.3 & 9 & 7 & 31 & 27 & 25 \\
\hline Financial intermediation and business activity & 0.4 & 12 & 9 & 36 & 26 & 17 \\
\hline $\begin{array}{l}\text { Public administration, education, health, } \\
\text { recreation, other services }\end{array}$ & 0.5 & 13 & 11 & 53 & 14 & 9 \\
\hline
\end{tabular}
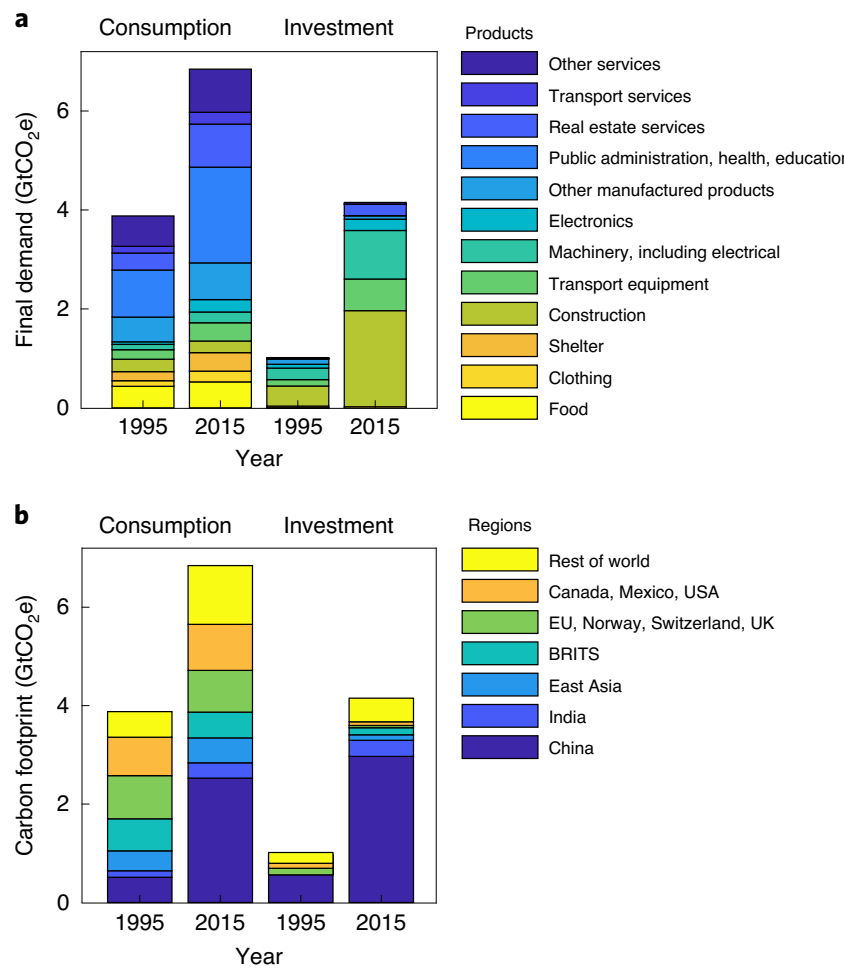

Fig. 2 | The material-related carbon footprint of final demand. a,b, The portion of the carbon footprint of final demand that has been caused by materials, organized by product demanded (a) and country/region (b). Final demand consists of consumption (by households, non profits and the government) and net investment (gross fixed capital formation minus consumption of fixed capital). The regions represent the entire world. BRITS: Brazil, Russia, Indonesia, Turkey, South Africa. emissions, although the current analysis also shows that the stock is not necessarily static and that consumption still plays an important role. Similar build-ups of structures, transport systems and factories are foreseeable in regions such as India and sub-Saharan Africa, where population growth is still rapid and urbanization is at an earlier stage. Finding ways to urbanize and develop in a manner that relies on less materials and building lighter structures and collective transportation systems are potential approaches to reducing the material stock required for a modern society ${ }^{34,35}$.

\section{Online content}

Any methods, additional references, Nature Research reporting summaries, source data, extended data, supplementary information, acknowledgements, peer review information; details of author contributions and competing interests; and statements of data and code availability are available at https://doi.org/10.1038/ s41561-021-00690-8.

Received: 15 May 2019; Accepted: 22 December 2020;

Published online: 15 February 2021

\section{References}

1. Fischedick, M. et al. in Climate Change 2014: Mitigation of Climate Change (eds Edenhofer, O. et al.) Ch. 10.3 (IPCC, Cambridge Univ. Press, 2014).

2. International Energy Agency. Energy Technology Perspectives 2017 (OECD, 2017).

3. Allwood, J. M., Cullen, J. M. \& Milford, R. L. Options for achieving a $50 \%$ cut in industrial carbon emissions by 2050. Environ. Sci. Technol. 44, 1888-1894 (2010)

4. Worrell, E. \& Carreon, J. R. Energy demand for materials in an international context. Phil. Trans. R. Soc. A 375, 20160377 (2017).

5. Allwood, J. M., Ashby, M. F., Gutowski, T. G. \& Worrell, E. Material efficiency: providing material services with less material production. Phil. Trans. R. Soc. A 371, 20120496 (2013).

6. Worrell, E., Allwood, J. M. \& Gutowski, T. G. The role of material efficiency in environmental stewardship. Annu. Rev. Env. Resour. 41, 575-598 (2016) 
7. Scott, K., Giesekam, J., Barrett, J. \& Owen, A. Bridging the climate mitigation gap with economy-wide material productivity. J. Ind. Ecol. 23, 918-931 (2019).

8. Stahel, W. R. The circular economy. Nature 531, 435-438 (2016).

9. Geng, Y., Sarkis, J. \& Bleischwitz, R. How to globalize the circular economy. Nature 565, 153-155 (2019).

10. Zhu, J., Fan, C., Shi, H. \& Shi, L. Efforts for a circular economy in china: a comprehensive review of policies. J. Ind. Ecol. 23, 110-118 (2019).

11. Material Efficiency in Clean Energy Transitions (IEA, 2019).

12. Pauliuk, S., Arvesen, A., Stadler, K. \& Hertwich, E. G. Industrial ecology in integrated assessment models. Nat. Clim. Change 7, 13-20 (2017).

13. Hertwich, E. G. et al. Material efficiency strategies to reducing greenhouse gas emissions associated with buildings, vehicles, and electronics - a review. Environ. Res. Lett. 14, 043004 (2019).

14. Stadler, K. et al. EXIOBASE3 - developing a time series of detailed environmentally extended multi-regional input-output tables. J. Ind. Ecol. 22, 502-515 (2018).

15. Wiedmann, T. O. \& Lenzen, M. Environmental and social footprints of international trade. Nat. Geosci. 11, 314-321 (2018).

16. Malik, A., McBain, D., Wiedmann, T. O., Lenzen, M. \& Murray, J. Advancements in input-output models and indicators for consumption-based accounting. J. Ind. Ecol. 23, 300-312 (2019).

17. Dietzenbacher, E. \& Lahr, M. L. Expanding extractions. Econ. Syst. Res. 25, 341-360 (2013).

18. Duarte, R., Sánchez-Chóliz, J. \& Bielsa, J. Water use in the Spanish economy: an input-output approach. Ecol. Econ. 43, 71-85 (2002).

19. Dietzenbacher, E., van Burken, B. \& Kondo, Y. Hypothetical extractions from a global perspective. Econ. Syst. Res. 31, 505-519 (2019).

20. Södersten, C.-J. H., Wood, R. \& Hertwich, E. G. Endogenizing capital in MRIO models: the implications for consumption-based accounting. Environ. Sci. Technol. 52, 13250-13259 (2018).

21. Hertwich, E. G. \& Wood, R. The growing importance of scope 3 greenhouse gas emissions from industry. Environ. Res. Lett. 13, 104013 (2018).

22. Lenzen, M. Double-counting in life cycle calculations. J. Ind. Ecol. 12, 583-599 (2008).

23. Dente, S. M. R. et al. Effects of a new supply chain decomposition framework on the material life cycle greenhouse gas emissions-the Japanese case. Resour. Conserv. Recycl. 143, 273-281 (2019).
24. Dente, S. M. R., Aoki-Suzuki, C., Tanaka, D. \& Hashimoto, S. Revealing the life cycle greenhouse gas emissions of materials: the Japanese case. Resour. Conserv. Recycl. 133, 395-403 (2018).

25. Cabernard, L., Pfister, S. \& Hellweg, S. A new method for analyzing sustainability performance of global supply chains and its application to material resources. Sci. Total Environ. 684, 164-177 (2019).

26. Le Quéré, C. et al. Global carbon budget 2018. Earth Syst. Sci. Data 10, 2141-2194 (2018)

27. Huang, B. et al. Building material use and associated environmental impacts in China 2000-2015. Environ. Sci. Technol. 52, 14006-14014 (2018).

28. Cai, W., Wan, L., Jiang, Y., Wang, C. \& Lin, L. Short-lived buildings in China: impacts on water, energy, and carbon emissions. Environ. Sci. Technol. 49, 13921-13928 (2015)

29. Kawase, K. China's housing glut casts pall over the economy. Nikkei Asia https://asia.nikkei.com/Spotlight/The-Big-Story/China-s-housing-glutcasts-pall-over-the-economy (2019).

30. Guan, D. et al. Structural decline in China's $\mathrm{CO}_{2}$ emissions through transitions in industry and energy systems. Nat. Geosci. 11, 551-555 (2018)

31. Moynihan, M. C. \& Allwood, J. M. Utilization of structural steel in buildings. Proc. R. Soc. A 470, 20140170 (2014).

32. Heeren, N. \& Hellweg, S. Tracking construction material over space and time: prospective and geo-referenced modeling of building stocks and construction material flows. J. Ind. Ecol. 23, 253-267 (2019).

33. Müller, D. B. et al. Carbon emissions of infrastructure development. Environ. Sci. Technol. 47, 11739-11746 (2013).

34. Hertwich, E. G., Lifset, R., Heeren, N., Ali, S. \& Pauliuk, S. Resource Efficiency and Climate Change: Emission Reductions From Material-Efficient Homes and Cars (United Nations Environment Programme, 2020).

35. Swilling, M. et al. The Weight of Cities: Resource Requirements of Future Urbanization (International Resource Panel, United Nations Environment Programme, 2018)

Publisher's note Springer Nature remains neutral with regard to jurisdictional claims in published maps and institutional affiliations.

(c) The Author(s), under exclusive licence to Springer Nature Limited 2021 


\section{Methods}

Method choice. The present work uses input-output methods that have long been used to describe economic relations among sectors of the economy and have recently been shown to be useful for environmental analysis, especially when national tables are combined with trade data to construct a global table and when complemented by emission and resource-consumption data. Such MRIO tables are now the preferred tools for material ${ }^{36,37}$, carbon ${ }^{38}$ and other footprinting ${ }^{15}$. Alternatively, life-cycle inventory data could be combined with material-consumption statistics to provide information on the impacts of various materials, as has been done for the global use of metals ${ }^{39,40}$. Such an analysis could correct for double counting and, with material-flow analysis, could be extended to the use of materials. It would be difficult to address the materials' contribution to the carbon footprints of final products, or to the materials' share of emissions in the carbon footprint of other products.

Data and scope. The modelling is based on version 3.6 of the EXIOBASE MRIO database $\mathrm{e}^{14,41}$, in which different materials were detailed on the basis of data from mineral statistics ${ }^{42,43}$ and IEA energy statistics ${ }^{44}$. EXIOBASE 3.6 represents the world economy in 43 individual territories and 6 aggregated regions. $\mathrm{CO}_{2}$ emissions from fossil fuel combustion and industrial processes such as iron and clinker production, methane emissions from agriculture and the energy system, and nitrous oxide emissions from agriculture are the most important sources of GHG emissions. Emissions from land-use change were not included, because they cannot be clearly allocated to a specific production activity, and $\mathrm{CO}_{2}$ absorption in the growth of wood or through the carbonation of cement was ignored ${ }^{45}$. These omissions result in potential errors connected to wood, pulp and paper, and an overestimate of the climate impact of cement and plaster.

The production and the consumption of up to 200 products are modelled in each region, including the following materials: iron and steel; aluminium; copper; precious metals; lead, zinc and tin; other non-ferrous metals; cement, lime and plaster; stone; sand and clay; other non-metallic minerals; glass; wood; pulp; paper; rubber and plastic; and basic plastics. Note that this is a product-by-product table, therefore inputs are to production processes, not economic sectors. The material-efficiency work by the IEA ${ }^{11}$, by comparison, addresses iron and steel, aluminium, cement, pulp and paper, and chemicals. It specifies energy use but does not quantify related or other upstream emissions. Other MRIO tables do not offer the level of detail on different materials presented here, and plastics are commonly grouped with other chemicals. Furthermore, data on the consumption of capital are not available, making it impossible to carry out the modelling presented here without more data development.

Endogenization of capital. The use of capital goods such as machinery, buildings and vehicles in the production of goods and services was included in the carbon-footprint assessment by using the approach and data in ref. ${ }^{20}$. In this methodology, the consumption of fixed capital is treated as an input to production, with the required material demands, whereas the gross fixed capital formation, which normally is treated as a category of final demand, is replaced by the net fixed capital formation, reflecting only the investment above the consumption of fixed capital, which can be seen as expanding production capacity. In this manner, the carbon footprint of a product includes the emissions associated with producing the machinery used in the product's production. The annual table is still balanced and reflects the annual emissions, including those of material production. However, the disadvantage of this approach is that the technology assumed to be used for producing the capital goods is the current technology, their 'carbon replacement value ${ }^{33}$ and not the likely higher historical costs. Alternative approaches in which emissions associated with current capital formation are allocated to future years of capital use could remedy this problem ${ }^{46}$ but do not yet offer the same capital product detail used here. To investigate the importance of gross fixed capital formation, the carbon footprint of gross fixed capital is also calculated (Extended Data Fig. 2), with the total material-related carbon footprint of final consumption, plus investment covering emissions from material production in that year, plus a representation of emissions of the previous years associated with the capital consumed in the production of materials in the given year.

Input-output methods. In an input-output table, the matrix $A$ of input coefficients describes the technology of the economy, with each column representing the intermediate inputs required to produce a unit output of a product. The matrix $Y$ represents the final demand for products, and the vector $\mathbf{x}$ represents the production volume. The market balance in a closed or global economy shows that the total output needs to satisfy both the required intermediate inputs and the final consumption, $A \mathbf{x}+Y \mathbf{i}=\mathbf{x}$, where $\mathbf{i}$ is a vector of ones that sums over the preceding matrix. This system of linear equations written in matrix notation can be solved for the total production volume, yielding the Leontief demand-pull model, $\mathbf{x}=(I-A)^{-1} \mathbf{y}=L \mathbf{y}$, where $\mathbf{y}$ is an arbitrary unit of final demand and $I$ is an identity matrix of size $A$. $L$ is the Leontief inverse, which specifies the production volumes per unit final demand from each sector.

The matrix or row vector $\pi$ represents the input of production factors (or value added), such as capital, labour, and land, to produce a unit output in each sector. Together, $A$ and $\pi$ represent the technology of the economy. The firm or production balance indicates that the price of each product is the sum of the costs of intermediate inputs and the costs of factor inputs, or the value added, per unit output. Writing this for each production process gives $\mathbf{p} A+\boldsymbol{\pi}=\mathbf{p}$. Solving for the price of goods, we obtain the Leontief price model, $\mathbf{p}=\boldsymbol{\pi}(I-A)^{-1}=\boldsymbol{\pi} L$.

The emissions per unit output are contained in the matrix $S$ (one line per pollutant) and are weighted with the characterization vector $\mathrm{c}$ of 100 -year global warming potentials to obtain $\mathrm{CO}_{2} \mathrm{e}$, a row vector. To simplify the notation, the row vector $\mathbf{s}=\mathbf{c S}$ signifies the GHG emissions in $\mathrm{CO}_{2}$ e per unit output. The Leontief demand-pull model can be used to calculate the carbon footprint multiplier, that is, the cradle-to-gate GHG emissions to produce one unit of each product, $\mathbf{m}=\mathbf{c} S L=\mathbf{s} L$. Note the similarity between the multiplier for emissions and the price. The total carbon footprint of a final consumption basket $\mathbf{y}$ is given by $E=\mathbf{c S L y}$. If $\mathbf{y}$ only describes final consumption, there is no double counting, because all emissions are allocated to final consumption.

This Leontief demand approach to the quantification of the cradle-to-gate environmental impacts and carbon footprints is widely accepted and can be applied to any final product ${ }^{15,16}$. It could, in principle, also be applied to the materials in question. However, materials are required to produce materials. In fact, there is very little final demand for materials; the final demand is for products, including machinery and structures, made from materials and services created with the help of these products. Accounting only for materials purchased by final consumers would grossly underestimate the importance of materials for GHG emissions. An application of the total Leontief multiplier to gross output (that is, total material production) does not yield the proper total environmental impacts ${ }^{22}$ because of double counting ${ }^{21,22}$. The HEM $^{17,47,48}$ offers a way in which the economy-wide impact of material production (or any other intermediate inputs) can be estimated exactly while avoiding double counting. It does so by quantifying the production volumes and emissions not related to material production and by identifying the production activities and emissions related to materials as the remainder.

HEM is used in regional and structural economics to study forward and backward linkages among sectors, as well as the potential economic consequences of disasters and acts of terror ${ }^{17,18,47,49}$. A recent study ${ }^{19}$ argued that HEM cannot be used in global models, because the extracted product is often seen as being imported (for example, see refs. ${ }^{18,49}$ and Extended Data Fig. 4), and there is no place from which to import in a global model. The following section shows that HEM can be applied broadly to any system for which the basic input-output accounting identities and Leontief production functions hold. The extraction of a sector is only hypothetical and provides an identification of relationships within the input-output table. By implication, it also applies to global and multiregional models, where any number of production processes, individual inputs, or a fraction thereof can be extracted.

HEM. I would like to quantify the use of various production processes $\mathbf{x}^{o}$ in the economy required to satisfy both the intermediate and final consumption of a specific product, or group of products, signified by $o$. Furthermore, I would like to quantify the use of factors in the production of those goods, and the share of the cost/factors of producing $o$ in the price/factor requirements of other goods. Imagine now that we engage in an experiment where we trace the expenditure on $o$ through the value chain by splitting the input-output description of the economy into two additive parts: one describing the complete production of intermediate and final demand for products $o$, including the production of products ${ }^{\star} \notin o$ serving as intermediate input to the production of $o$, and the other describing the final demand for the remaining products ${ }^{*}$ (Extended Data Fig. 4),

$$
A=A^{*}+A^{o} ; \mathbf{y}=\mathbf{y}^{*}+\mathbf{y}^{o}
$$

where the production volume not involved with the production of $o$ is given by

$$
A^{*} \mathbf{x}^{*}+\mathbf{y}^{*}=\mathbf{x}^{*} \rightarrow \mathbf{x}^{*}=\left(I-A^{*}\right)^{-1} \mathbf{y}^{*}=L^{*} \mathbf{y}^{*}
$$

The hypothetical extraction theorem says that the output required to satisfy the intermediate and final demands for the extracted product, $o$, can be calculated as the difference in the production volume of the unperturbed system and the system where certain intermediate and final demand has been extracted.

$$
\mathbf{x}^{o}=L \mathbf{y}-L^{*} \mathbf{y}^{*}
$$

Alternatively, the value can be identified as

$$
\mathbf{x}^{o}=L \mathbf{y}^{o}+L A^{o} L^{*} \mathbf{y}^{*}
$$

and the two solutions can be shown to be equivalent because $L A^{\circ} L^{*}=L-L^{*}$. The identification of the production volume of extracted materials through equation (4) corresponds to the identification of sectors by ref. ${ }^{25}$, based on ref. ${ }^{23}$. It can be seen from equation (3) that HEM avoids double counting.

The production balance equation $(5 \mathrm{a})$ can be used to identify the contribution of the extracted products to the price of the non-extracted products (Extended Data Fig. 4). It can be solved using the solution to the production balance of the extracted products $\mathbf{p}^{o}=\pi^{o} L$. 


$$
\begin{gathered}
\mathbf{p}^{*}=\mathbf{p}^{*} A^{*}+\mathbf{p}^{o} A^{o}+\pi^{*} \\
\mathbf{p}^{*}=\pi^{*} L^{*}+\pi^{o} L A^{o} L^{*}
\end{gathered}
$$

Here, the second term of the right-hand side of the Leontief price model in equation (5b) represents the value added associated with producing the extracted inputs, that is, the materials. For equations (1) and (2) to hold, $\mathbf{p}^{\circ}=\mathbf{p}^{*}=\mathbf{p}$ and $\boldsymbol{\pi}^{o}=\boldsymbol{\pi}^{\star}=\boldsymbol{\pi}$. Given that emissions and other factor inputs can be treated in the same manner as the value added, the carbon footprint of material production in other products $\left(y^{*}\right)$ is given by the multiplier

$$
\mathbf{m}^{o}=\mathbf{s} L A^{o} L^{*}=\mathbf{s}\left(L-L^{*}\right)
$$

To determine the total emissions associated with the production of extracted inputs, there are now two ways of calculating those. One is simply to multiply the production volume required to produce the extracted product by the respective factor coefficients:

$$
E^{o}=\mathbf{s x}^{o}
$$

The second is to sum the respective multipliers over the final demand for extracted and non-extracted products:

$$
E^{o}=\mathbf{s} L \mathbf{y}^{o}+\mathbf{s} L A^{o} L^{*} \mathbf{y}^{*}
$$

The respective vector and matrix multiplications entail summations over contributions of different producing processes, trades and final demands. It is of interest to distinguish these through a decomposition of the matrix multiplication. $\boldsymbol{\Gamma}$ symbolizes the decomposition of the total factor costs of producing the extracted product, here, the carbon footprint of materials:

$$
\Gamma^{\mathbf{x}}=\mathbf{s} \widehat{\mathbf{x}^{o}}
$$

by emitting process (Fig. 1a and Table 1a);

$$
\mathbf{\Gamma}^{\mathrm{FU}}=\mathbf{s} L \widehat{\mathbf{y}^{0}}+\mathbf{s} L A^{o} \widehat{\mathbf{x}^{*}}
$$

by first use (Fig. 1c and Table 1b)

$$
\Gamma^{\mathbf{y}}=\mathbf{s} L \widehat{\mathbf{y}^{o}}+\mathbf{s} L A^{o} L^{*} \widehat{\mathbf{y}^{*}}
$$

by product in final consumption (Fig. 2 and Table 1c);

$$
\boldsymbol{\Gamma}^{M}=\hat{\mathbf{m}} \mathbf{y}^{o}+\hat{\mathbf{m}} A^{o} L^{*} \mathbf{y}^{*}
$$

by material (Fig. 1b).

Here, the entire production of material(s) $j$ was extracted by setting all intermediate and final demand for both domestically produced and imported inputs to other sectors and the final demand to zero $\left(A_{j . .}^{*}=0 ; Y_{j . .}^{*}=0\right)$. As a previous study ${ }^{17}$ has shown, it is not necessary to set cells to zero through partial extraction; one can also set them to a different value. One can also extract only a single input, such as the use of steel in the automotive industry, as long as equation (1) holds.

The identification of individual materials. If a single material is extracted, other materials will have been used in its production, for example, steel and copper in the machinery and cement in the infrastructure. Some materials are intermediate stages to other materials, such as pulp for paper production. If all materials are extracted individually, the total emissions obtained by summing over the $E^{o}$ for all materials will thus contain double counting. The next section describes a strategy to identify such interdependencies. To avoid double counting and correctly estimate the emissions associated with each material going to the production of downstream products and apart from the inputs of other assessed materials, equation (11) was used for the case where all materials have been extracted at the same time. The calculation method implies that emissions during the production of zinc used as a steel alloy are counted as being part of the carbon footprint of steel, not that of zinc, and the carbon footprint of zinc is only for zinc used outside material production.

Interdependencies of different materials. To determine the use of materials as direct or indirect inputs in the production of other materials shown in Supplementary Table 1, a single line was added to the extension matrix $S$ for each material $j$, being unity for each production process of the respective material and zero otherwise. With this $S$, equation (8) then yields the amount $\lambda_{i j}$ of materials $i$ required to produce each individually extracted material $j$, and $\lambda_{i i}$ is the production volume of material $i$. Supplementary Table 1 contains the results for all materials. It displays interdependencies, such as the use of most pulp for paper production or the use of nearly half of basic plastics in rubber and plastic production. For most materials, of the order of $10-20 \%$ of the production volume is used in the production of materials.
The analysis was conducted at the country/regional level, with each material being extracted in all regions at once, and the results were aggregated to the global level.

Uncertainty. The present assessment of the carbon footprint of materials, the use of materials and the material-related component of the carbon footprint relies on a MRIO table constructed for this type of analysis. Different MRIO tables have been constructed by using different principles and data sources, yielding different results in footprint studies ${ }^{50}$. Important sources of uncertainty are related to the assumed homogeneity of products or sectors and related to that, the aggregation of products ${ }^{51}$, and the uncertainty in the emissions data. By using a Monte Carlo analysis of country-level consumption-based carbon-emission accounts across different MRIO databases, a previous study ${ }^{52}$ found a coefficient of variation (normalized standard deviation) of $2-16 \%$ across countries. It found much higher product-level uncertainty ranging from 10 to $200 \%$, depending on the product. Similar uncertainties apply to the results reported in this manuscript, with higher relative uncertainties for smaller production volumes. We cannot necessarily assume that the uncertainties of individual country products are independent from each other; there may be issues associated with the collection of energy-use data or the disaggregation procedure that afflict all estimates for a specific material in the same manner ${ }^{52}$. Uncertainties for the most recent years are higher than those up to 2011; indeed, the input-output tables were detailed on the basis of a set of assumptions and preliminary data, because final national account data were not yet available. Another study ${ }^{39}$ projected the carbon footprint of global metal consumption in 2008 by using life cycle assessment data and global production volumes of metals. They estimated $3.1 \mathrm{GtCO}_{2} \mathrm{e}$, compared with 3.7 estimated here. The contribution of iron and steel, aluminium, and other metals was 2.4, 0.4 and $0.3 \mathrm{Gt}$, respectively, compared with $2.8,0.5$ and $0.4 \mathrm{Gthere}$. Although the widely acknowledged issue of cut-off errors in life cycle assessment would offer a convenient explanation, there can be many other causes for this discrepancy. Yet the comparison provides some comfort that the first significant figure is correct.

\section{Data availability}

A public version of EXIOBASE 3 is available on Zenodo at https://doi.org/10.5281/ zenodo.3583071. The public version differs slightly from the version that was used in the present research, which makes use of proprietary third-party energy data from the IEA. The private version of the data is available from the author upon request by anybody who has obtained a licence to the IEA Energy Statistics and Energy Balances. Source data are provided with this paper.

\section{Code availability}

MatLab code is available on Zenodo at https://doi.org/10.5281/zenodo.4280697.

\section{References}

36. Giljum, S., Bruckner, M. \& Martinez, A. Material footprint assessment in a global input-output framework. J. Ind. Ecol. 19, 792-804 (2015).

37. Wiedmann, T. O. et al. The material footprint of nations. Proc. Natl Acad. Sci. USA 112, 6271-6276 (2015).

38. Hertwich, E. G. \& Peters, G. P. Carbon footprint of nations: a global, trade-linked analysis. Environ. Sci. Technol. 43, 6414-6420 (2009).

39. Nuss, P. \& Eckelman, M. J. Life cycle assessment of metals: a scientific synthesis. PLoS ONE 9, e101298 (2014).

40. van der Voet, E. et al. Environmental Risks and Challenges of Anthropogenic Metals Flows and Cycles (United Nations Environment Programme, 2013).

41. Stadler, K. et al. EXIOBASE 3 (Norwegian University of Science and Technology, 2019); https://doi.org/10.5281/zenodo.3583071

42. World Mineral Statistics (BGS, 2018).

43. Reichl, C., Schatz, M. \& Zsak, G. World Mining Data Vol. 29 (Austrian Federal Ministry of Agriculture, Regions and Tourism, 2014).

44. World Energy Statistics (Edition 2016) (IEA, 2016); https://doi. org/10.1787/03a28cba-en

45. Xi, F. et al. Substantial global carbon uptake by cement carbonation. Nat. Geosci. 9, 880-883 (2016).

46. Chen, Z.-M. et al. Consumption-based greenhouse gas emissions accounting with capital stock change highlights dynamics of fast-developing countries. Nat. Commun. 9, 3581 (2018).

47. Schultz, S. Approaches to identifying key sectors empirically by means of input-output analysis. J. Dev. Stud. 14, 77-96 (1977).

48. Zhang, L., Liu, B., Du, J., Liu, C. \& Wang, S. $\mathrm{CO}_{2}$ emission linkage analysis in global construction sectors: alarming trends from 1995 to 2009 and possible repercussions. J. Clean. Prod. 221, 863-877 (2019).

49. He, W., Wang, Y., Zuo, J. \& Luo, Y. Sectoral linkage analysis of three main air pollutants in China's industry: comparing 2010 with 2002. J. Environ. Manage. 202, 232-241 (2017)

50. Owen, A. Techniques for Evaluating the Differences in Multiregional Input-Output Databases (Springer, 2017).

51. Steen-Olsen, K., Owen, A., Hertwich, E. G. \& Lenzen, M. Effects of sector aggregation on $\mathrm{CO}_{2}$ multipliers in multiregional input-output analyses. Econ. Syst. Res. 26, 284-302 (2014). 
52. Rodrigues, J. F. D., Moran, D., Wood, R. \& Behrens, P. Uncertainty of consumption-based carbon accounts. Environ. Sci. Technol. 52, 7577-7586 (2018)

\section{Acknowledgements}

Language editing by A. Devismes. The work was conducted as part of the project 'Resource efficiency and climate change' of the International Resource Panel.

\section{Author contributions}

E.G.H. designed the research, conducted the calculations, interpreted the findings and wrote the manuscript.

\section{Competing interests}

The author declares no competing interests.

\section{Additional information}

Extended data is available for this paper at https://doi.org/10.1038/s41561-021-00690-8.

Supplementary information The online version contains supplementary material available at https://doi.org/10.1038/s41561-021-00690-8.

Correspondence and requests for materials should be addressed to E.G.H.

Peer review information Primary Handling Editor: Rebecca Neely.

Reprints and permissions information is available at www.nature.com/reprints. 


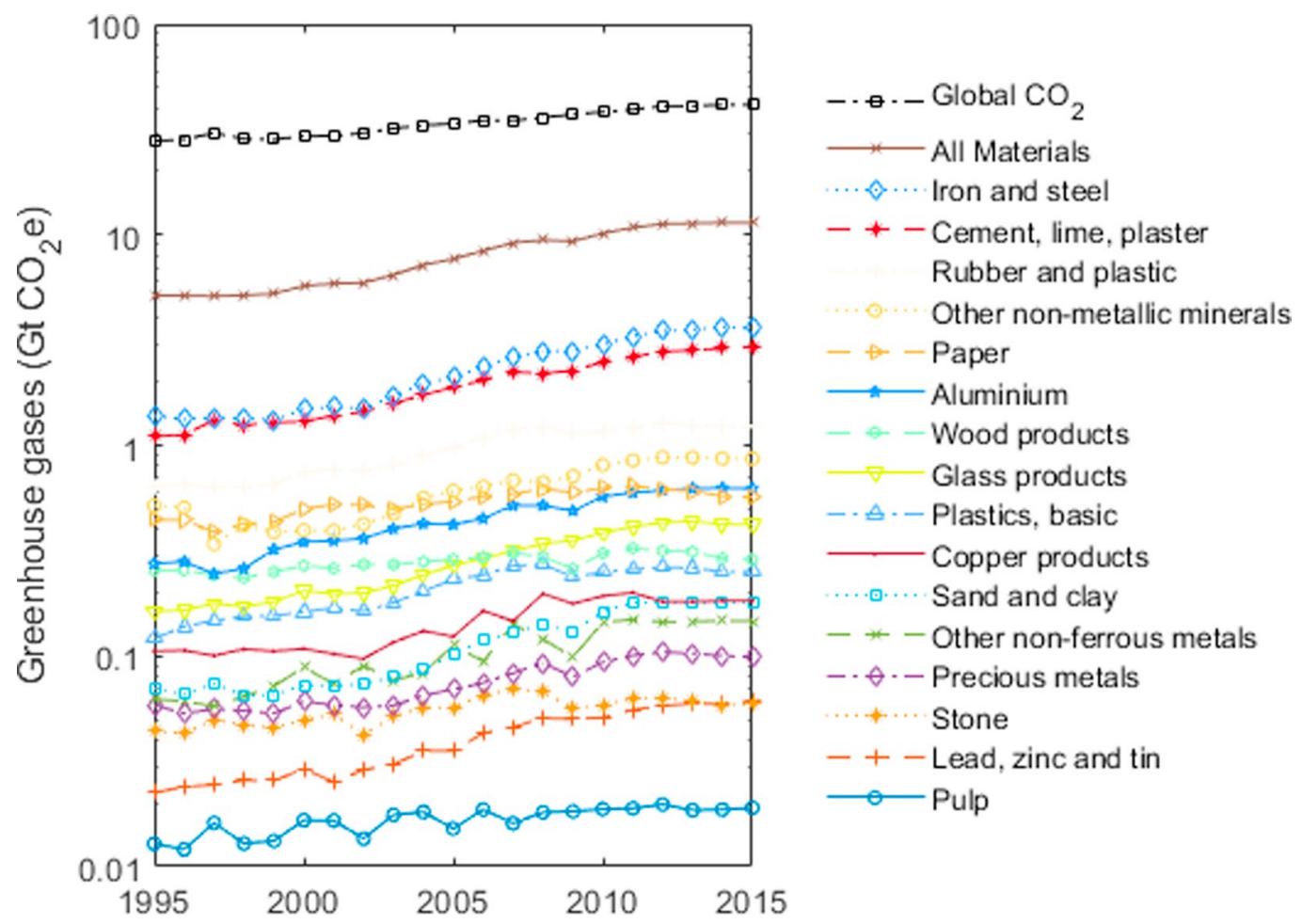

Extended Data Fig. 1 | Carbon footprint of the production of individual materials, compared to global $\mathrm{CO}_{2}$ emissions. Greenhouse gas emissions in the production of materials over the period 1995-2015. Materials are listed as represented in the input-output database EXIOBASE. For each material, emissions associated with the input of other materials are included. 


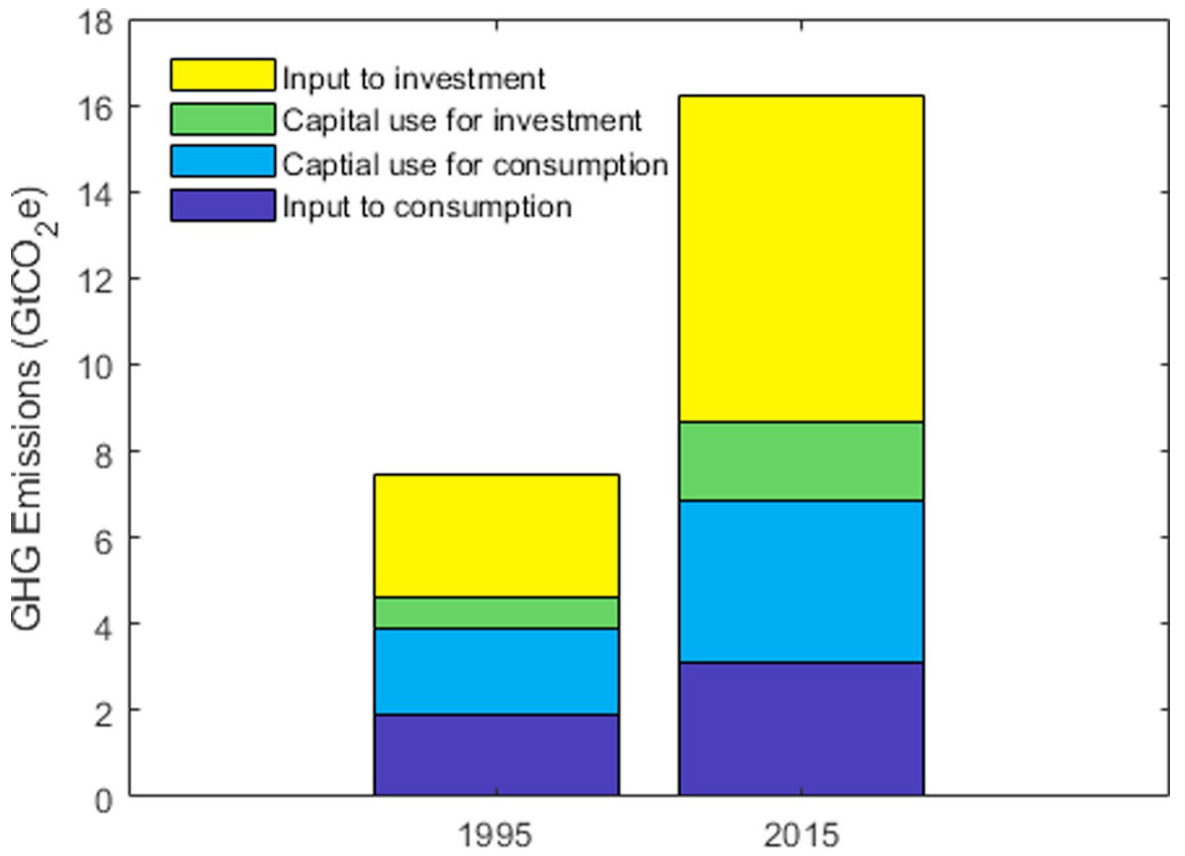

Extended Data Fig. 2 | Carbon footprint of investment and consumption. Production of consumer goods and services as well as investment products needs both direct inputs of materials with which these goods and services are produced, and the use of a capital stock in the form of buildings, equipment, machinery, and vehicles which is being depreciated in the process. The use of capital refers to materials that were produced in earlier years. Figure 2 showed the net investment. Here, the focus is in gross fixed capital formation, which is comprised of net investment and reinvestment (replacement of capital that has been depreciated in the given year). The input to consumption has grown by $64 \%$, the input to investment by $170 \%$. 


\section{NATURE GEOSCIENCE}
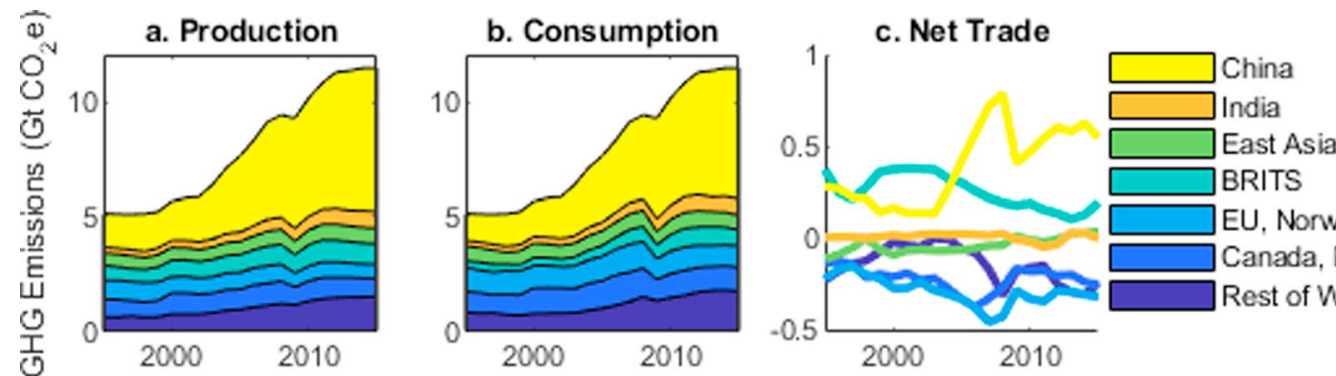

EU, Norway, Switzerland, UK

Canada, Mexico, USA

Extended Data Fig. 3 | Materials-related GHG emissions according to production- and consumption-based accounts, and net trade. GHG emissions by the country in which materials or their inputs are produced and emissions occur (a), the country in which final consumption relying on these materials happens (b), and net trade (c) that is, the difference between (a) and (b). China dominates export, followed by Brazil, Russia, Indonesia, Turkey and South Africa (BRITS). Europe and North America are the primary importers. The growth in both the production and consumption of materials was concentrated in China and the developing countries represented in the Rest of World. 

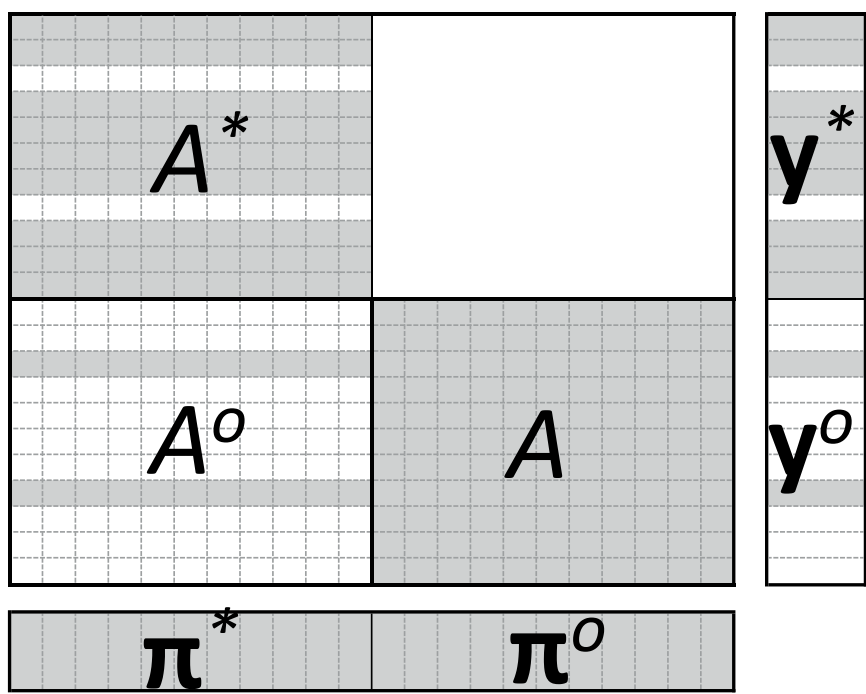

Extended Data Fig. 4 | Matrices used in the hypothetical extraction method. Columns represent inputs, and rows outputs of the input-output system. 